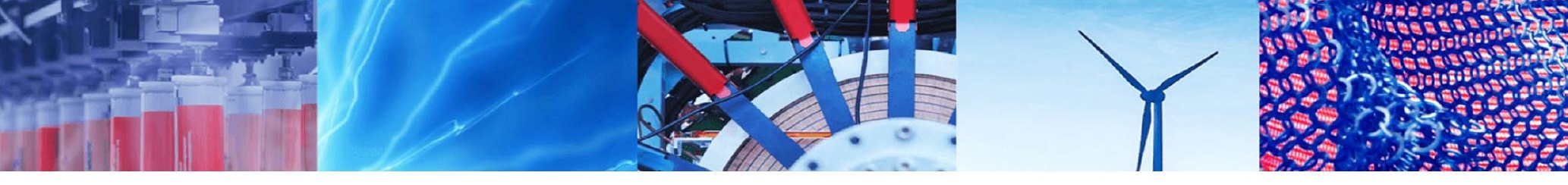

Research Article

\title{
Performance-tuning of PVA-based gel electrolytes by acid/PVA ratio and PVA molecular weight
}

\author{
Saeideh Alipoori ${ }^{1}$ - M. M. Torkzadeh ${ }^{2} \cdot$ Saeedeh Mazinani $^{3} \cdot$ Seyed Hamed Aboutalebi ${ }^{2,4,5} \cdot$ Farhad Sharif $^{1} \mathbb{D}$
}

Received: 5 September 2020 / Accepted: 7 January 2021 / Published online: 12 February 2021

(C) The Author(s) 2021 OPEN

\begin{abstract}
The significant breakthroughs of flexible gel electrolytes have attracted extensive attention in modern wearable electronic gadgets. The lack of all-around high-performing gels limits the advantages of such devices for practical applications. To this end, developing a multi-functional gel architecture with superior ionic conductivity while enjoying good mechanical flexibility is a bottleneck to overcome. Herein, an architecturally engineered gel, based on $\mathrm{PVA}_{\text {and }} \mathrm{H}_{3} \mathrm{PO}_{4}$ with different molecular weights of $\mathrm{PVA}$ for various $\mathrm{PVA} / \mathrm{H}_{3} \mathrm{PO}_{4}$ ratios, was developed. The results show the dependence of ionic conductivity on molecular weight and also charge carrier concentration. Consequently, fine-tuning of PVA-based gels through a simple yet systematic and well-regulated strategy to achieve highly ion-conducting gels, with the highest ionic conductivity of $14.75 \pm 1.39 \mathrm{mS} \mathrm{cm}^{-1}$ have been made to fulfill the requirement of flexible devices. More importantly, gel electrolytes possess good mechanical robustness while exhibiting high-elasticity (\%766.66 \pm 59.73$)$, making it an appropriate candidate for flexible devices.
\end{abstract}

Keywords Gel electrolyte · Poly (vinyl alcohol) · lonic conductivity · Mechanical properties

\section{Introduction}

Flexible, ultrathin, and lightweight energy storage devices have attracted increasing attention to fulfill the urgent needs of portable and wearable electronic gadgets, including smartphones, roll-up displays, and photovoltaic cells. Therefore, a flexible polymer electrolyte is a favourable choice for the design and fabrication of such energy storage devices because of the unique properties, such as stretchability, ease of fabrication, excellent adhesive properties, and broad potential window. Among the solid-state polymer electrolytes, gel polymer electrolytes (GPEs) have emerged as a prominent candidate due to their flexibility, high ionic conductivity, and good mechanical properties [1-3].

However, tuning the many promises of such devices into reality has proved to be difficult, mainly due to the lack of all-around high-performing gel electrolytes. As such, a multifunctional gel-electrolyte architecture that exhibits superior ionic conductivity with good mechanical properties and flexibility is highly desirable. Consequently, the optimization of critical parameters such as ionic conductivity, mechanical properties, and flexibility is necessary for GPEs to be suitable for use in flexible electronics. GPEs typically consist of a polymer network and solvent in which the polymer network envelopes the liquid and

\footnotetext{
Supplementary material The online version contains supplementary material available at (https://doi.org/10.1007/s42452-021-04182-7) contains supplementary material, which is available to authorized users.

$\triangle$ Farhad Sharif, sharif@aut.ac.ir| ${ }^{1}$ Polymer Engineering \& Color Technology Department, Amirkabir University of Technology, Tehran, Iran. ${ }^{2}$ Condensed Matter National Laboratory, Institute for Research in Fundamental Sciences, $19395-5531$, Tehran, Iran. ${ }^{3}$ New Technologies Research Center (NTRC), Amirkabir University of Technology, Tehran, Iran. ${ }^{4}$ School of Nano Science, Institute for Research in Fundamental Sciences (IPM), Tehran, 19395-5531, Iran. ${ }^{5}$ Pasargad Institute for Advanced Innovative Solutions (PIAIS), 1991633361 Tehran, Iran.
} 
prevents it from escaping. The properties of GPEs depend on the structure of the polymer network forming the gel [2-6].

Recently, different polymers such as poly (ethylene oxide) (PEO), poly (vinyl alcohol) (PVA), poly (methyl methacrylate) (PMMA), poly (acrylonitrile) (PAN) and poly (vinylidene fluoride) (PVDF) have been used for the preparation of GPEs. The early studies of PEO-based gel electrolytes usually showed low ionic conductivity, due to high polymer crystallinity and low motion of polymer chains [7, 8]. The use of PMMA as a matrix in gel electrolytes revealed that PMMA does not affect the electrochemical stability of gel electrolytes and has low ionic conductivity. PAN and PVDF-based gel electrolytes let the formation of homogenous gel films but PAN is inactive in the ionic transport mechanisms. PVDF has a high dielectric constant which provides an increased number of charge carriers. Still it has low ionic conductivity because of highly crystalline nature and low interfacial chemical stability in lithium-based batteries. Among the listed polymeric hosts, PVA and PVA nanocomposites have been extensively investigated due to its excellent properties and potential applications in the various fields of science and technology. PVA is a prominent candidate because it is biodegradable, inexpensive, chemically stable, non-toxic, with a wide operation temperature and transparent film formation capability. Completely Hydrolyzed PVA has different properties than partially hydrolyzed PVA. Moreover, the semicrystalline nature of PVA is due to the hydroxyl groups of PVA absorbs a large amount of water that enhances the ionic conductivity [1, 3, 4, 8-13].

Gel polymer networks are solvated by a large amount of the trapped solvent that generally possesses high ionic conductivity. The ionic conductivity depends on the charge carrier concentration and carrier mobility. Mobility is inversely related to gel electrolytes' viscosity, which depends on the molecular weight of the polymer. Gel electrolytes have lower ionic conductivity than liquid electrolytes, but they do not require high safety encapsulation materials and have flexibility, which is necessary for wearable electronic devices $[1,3,10,11,14]$. Recently, Mishra et al. [15] studied the effect of Al2O3 on ionic conductivity of PVDF-HFP/PMMA blend nanocomposite gel electrolyte. The electrolyte with $6 \mathrm{wt} \% \mathrm{Al}_{2} \mathrm{O}_{3}$ showed the highest ionic conductivity due to the uniform dispersion of nanoparticles in the gel and enhanced the amorphic nature of the polymer. Sun et al. [16] added a novel redox additive $\mathrm{PySH}$ (2-mercapto pyridine) into the gel polymer electrolyte based on $\mathrm{PVA} / \mathrm{H}_{3} \mathrm{PO}_{4} / \mathrm{H}_{2} \mathrm{O}$, which dramatically increased ion diffusion and improved tensile and bending properties. Gao and coworkers [17] proved an enhancement in ionic conductivity of SiWA $/ \mathrm{H}_{3} \mathrm{PO}_{4} / \mathrm{PVA}$ gel electrolyte in the presence of nano-SiO ${ }_{2}$ and nano- $\mathrm{TiO}_{2}$ fillers.
The gel electrolyte based on $\mathrm{SiO}_{2}$ fillers had a higher water content and a more stable network structure for proton transport. Prajapati et al. [18] studied the effect of polyethylene glycol (PEG) as a plasticizer on a gel electrolyte ionic conductivity based on $\mathrm{PVA} / \mathrm{H}_{3} \mathrm{PO}_{4} / \mathrm{H}_{2} \mathrm{O}$. The highest value of ionic conductivity was obtained $\left(0.086 \mathrm{mS} \mathrm{cm}^{-1}\right)$ with an optimum amount of $30 \mathrm{wt} \%$. PEG. PEG molecules could increase the flexibility of polymer chains and mobility of ions as they penetrate between the polymer chains and reduce the polymer's crystallinity. Pavani et al. [19] developed a gel electrolyte based on $\mathrm{PVA} / \mathrm{KCl} / \mathrm{H}_{2} \mathrm{O}$ in the different weight ratios of $\mathrm{PVA} / \mathrm{KCl}$. X-ray diffraction (XRD) analysis was used to investigate the effect of salt on polymer structure. Pure PVA showed a peak at $23.6^{\circ}$, which decreased by increasing the amount of salt in the electrolyte. The absence of salt peaks in the XRD spectrum confirmed the complete dissolving of salt in the polymer matrix and increases the polymer's amorphous phase. The amorphous nature of the electrolyte leads to increased ion penetration and ion conduction. Moreover, they used scanning electron microscope (SEM) to study the morphology of the electrolyte. The results showed that by adding the salt to the polymer, the surface roughness and wrinkles of the polymer film are reduced due to the interaction of the salt with the polymer chains [3].

Manifestly, the recent studies suggest improving ionic conductivity for gel electrolytes, but the careful and detailed examination of mechanical properties required elaborate apparatuses and operational details; more importantly, the issue of superior ionic conductivity still exist. To this end, it is still necessary and of great significance to unendingly improve the ionic conductivity of gel electrolyte to achieve high-performance flexible solidstate electrolyte while still intrinsically possessing high flexibility and mechanical property. Here, we aim to fabricate a high performing flexible gel electrolyte for the first time. In this regard, gel electrolytes based on $\mathrm{PVA} / \mathrm{H}_{3} \mathrm{PO}_{4} /$ $\mathrm{H}_{2} \mathrm{O}$ with different molecular weights $(\mathrm{Mw})$ of $\mathrm{PVA}$ for various weight ratios of $\mathrm{PVA} / \mathrm{H}_{3} \mathrm{PO}_{4}$ were prepared to optimize the ionic conductivity, film formation, and mechanical properties. The acids $\mathrm{H}_{2} \mathrm{SO}_{4}$ and $\mathrm{H}_{3} \mathrm{PO}_{4}$ generally provide free ions in gel electrolytes, which act as charge carriers, and solvent helps in solvating the salt while serving as the conducting medium. The salt has large anions and low dissociation energy, whereas the used solvent must have high dielectric constant, low viscosity, high boiling point, and low melting point. $\mathrm{H}_{2} \mathrm{SO}_{4}$ is a strong acid, and unlike $\mathrm{H}_{3} \mathrm{PO}_{4}$ when combines with PVA, it shows redox reactions and has low cycle life compared to weak acids. Cross-linking agents for PVA chains like glutaraldehyde are very toxic and organic solvents such as $A C N$ and $P C$ are flammable, toxic, and expensive which limit operability of PVA-based gel electrolytes. Furthermore, $\mathrm{H}_{3} \mathrm{PO}_{4}$ provides 
more free ions than other acids at the same molar concentration, improving gel electrolytes $[2,4,20,21]$. Here, we present a guideline on how to engineer or consider the effect of $\mathrm{PVA} / \mathrm{H}_{3} \mathrm{PO}_{4}$ weight ratio and $\mathrm{Mw}$ of PVA on ionic conductivity and mechanical properties of the gels and tune the formulation that possibly can be applied to other polymers.

\section{Experimental}

\subsection{Materials}

Polyvinylalcohol (PVA, molecular weight; 27,000, 61,000, $125,000,195,000 \mathrm{~g} / \mathrm{mole}$, alcoholysis; $98 \%$ ) was obtained from Sigma-Aldrich [Mowiol, the product name for each molecular weight is 27000 (Mowiol 4-98), 61,000 (Mowiol 10-98), 125,000 (Mowiol 20-98), 195,000(Mowiol 56-98)]. Orthophosphoric acid (85\%) was purchased from Merck.

\subsection{Preparation of gel polymer electrolyte}

Gel polymer electrolyte was prepared in a water bath by dissolving $1 \mathrm{~g}$ of PVA in $10 \mathrm{~mL}$ distilled water with agitation at $90^{\circ} \mathrm{C}$ for $2 \mathrm{~h}$ until a homogeneous and low viscous solution obtained, followed by cooling at room temperature. Finally, under continuous stirring, the aqueous solution of $\mathrm{H}_{3} \mathrm{PO}_{4}$ was added to the viscous liquid. In the first section, the gel polymer electrolyte was prepared at different concentrations of $\mathrm{H}_{3} \mathrm{PO}_{4}$ in $\mathrm{H}_{2} \mathrm{O}(0.05,0.01,0.18,0.33,0.52$, $0.66,0.85$ and $0.99 \mathrm{~g} / \mathrm{mL}$ ) or the weight ratio of $\mathrm{PVA} / \mathrm{H}_{3} \mathrm{PO}_{4}$ was equal to $1 / 0.5,1 / 1,1 / 2,1 / 4,1 / 7,1 / 10,1 / 15$ and $1 / 20$, respectively, for constant PVA concentrations in $\mathrm{H}_{2} \mathrm{O}(0.09$ and $0.08 \mathrm{~g} / \mathrm{mL}$ ). In the next step, the gel polymer electrolyte was made at different concentrations of PVA in $\mathrm{H}_{2} \mathrm{O}$ $(0.12,0.11,0.09,0.08,0.07,0.06,0.05$ and $0.03 \mathrm{~g} / \mathrm{mL})$ for the sample with the highest conductivity in the first section.

Finally, the viscous solutions were cast into PS molds and dried at room temperature. The dried films were peeled off the molds, and a free-standing $\mathrm{PVA} / \mathrm{H}_{3} \mathrm{PO}_{4}$ gel electrolyte was obtained for further tests.

\subsection{Characterization tests}

Fourier transform infrared spectrometer (FTIR) (Thermo Scientific, NICOLET iS10) in ATR mode was used to record the Infrared absorption spectra of gel electrolyte samples in the range of $500-4000 \mathrm{~cm}^{-1}$. The vibrational transition frequencies were reported in wavenumbers $(\mathrm{cm}-1)$. Ultraviolet-Visible (UV-Vis) spectroscopy was performed using SPECORD (210-222K433) in the spectra range from 190 to $800 \mathrm{~nm}$. Scanning electron microscopy (SEM) was used to study the samples' morphology with HITACHI, SU3500.
The crystalline structure of the samples was tested by X-ray diffraction (XRD) (PRO X'Pert MPD PANalytical Company) under Cu Ka of radiating $(\lambda=1.540 \AA), 40 \mathrm{kV}$ tube voltage, $40 \mathrm{~mA}$ tube current, scanning from 2 to $80^{\circ}$ at continuous scan type. The crystallinity degree is calculated based on the following formula:

$X(\%)=100 A c /(A c+A a)$

where $\mathrm{Aa}$ and $\mathrm{Ac}$ is the experimental integrated intensity of the amorphous and crystalline phase; respectively.

The total conductivity of the polymer electrolyte solutions was determined with a conductivity meter using ATRON. The processor converts the electrical current to the electrical resistance according to the Ohm's law;

$\mathrm{R}=\mathrm{V} / \mathrm{I}$

$R$ is the electrical resistance in ohm, $V$ is the cell voltage in volts $(\mathrm{V})$, and $\mathrm{I}$ is the electrical current in amperes (A) [22].

Conductance $(\mathrm{G})$ is the inverse of electrical resistance, and the conductivity of the electrolyte $(\sigma)$ is obtained by multiplying to solute constant (distance between two electrodes $(L)$ to the contact area of the electrolyte with the electrodes $(A)$ ).

$\mathrm{G}=1 / \mathrm{R}$

$\sigma=\mathrm{G} * \mathrm{~L} / \mathrm{A}$

$\sigma$ is the electrolyte conductivity in Siemens per centimeter $(\mathrm{S} / \mathrm{cm})[22]$.

The total conductivity measurement was repeated three times for each sample. The ionic conductivity of gel polymer electrolyte films was determined by AC impedance using BIOLOGIC, VSP300 system in the frequency range of $100 \mathrm{MHz}$ to $100 \mathrm{kHz}$, operation window of (0-1) $\mathrm{V}$ at $24{ }^{\circ} \mathrm{C}$ and relative humidity of $22 \%$. The sample was sandwiched between two stainless steel electrodes with a testing area of $1 \mathrm{~cm}^{2}$. Cyclic stability of GPEs was measured using BIOLOGIC, VSP300 charge-discharge system at $1 \mu \mathrm{A} \mathrm{g}^{-1}$ for 2000 cycles. The specific capacitance was evaluated from charge-discharge curves according to the following equation;

$C s=21 / m\left(\frac{d V}{d t}\right)$

where I (A) is the discharge current, $\mathrm{m}(\mathrm{g})$ is the weight of active gel film on both electrodes, and $\frac{d V}{d t}$ is the slope of the discharge curve [23]. GALDABINI Sun 2500 mechanical testing machine with $1 \mathrm{KN}$ force sensor was used to study the mechanical properties of gel films prepared in a rectangular shape with a dimension of $1 \times 10 \mathrm{~cm}$ and repeated three times for each sample. Firstly, each sample 
was fixed between two grips with a gauge length of $5 \mathrm{~cm}$ followed by stretching at a constant rate of $50 \mathrm{~mm} / \mathrm{min}$ and room temperature till it broke. The weight percentage of water at a different time in gel electrolytes was determined experimentally. The weight change of gel electrolytes was recorded during drying at a regular time. Water retention is defined as (W0-We) $/ \mathrm{Wg} \times 100$, in which W0 is the weight of initial water, We are the weight of evaporated water, and $\mathrm{Wg}$ is the weight of gel film at each time. The weight change of each sample was repeated three times.

\section{Results and discussion}

\subsection{Structural characterization}

FTIR spectra for pure PVA and PVA/ $\mathrm{H}_{3} \mathrm{PO}_{4} / \mathrm{H}_{2} \mathrm{O}$ gel electrolyte film are given in Fig. 1 [24]. The absorption peaks of pure PVA at 3270, 2927, 1714, 1420, 1326, 1086, 914 and $825 \mathrm{~cm}^{-1}$ are assigned to the $\mathrm{O}-\mathrm{H}$ stretching, $\mathrm{C}-\mathrm{H}$ stretching, $\mathrm{C}=\mathrm{O}$ stretching, $\mathrm{C}-\mathrm{H}$ wagging, $\mathrm{C}-\mathrm{O}$ stretching of acetyl group, $\mathrm{C}-\mathrm{O}$ stretching of an acetate group and the two end peaks are related to the $\mathrm{C}-\mathrm{H}$ bending; respectively. The absorption peaks of gel electrolyte at 3293, $2780,1632,1417,1088,970,880$ and $811 \mathrm{~cm}^{-1}$ are attributed to the $\mathrm{O}-\mathrm{H}$ stretching, $\mathrm{C}-\mathrm{H}$ stretching, water absorption peak, $\mathrm{C}-\mathrm{H}$ wagging, $\mathrm{C}-\mathrm{O}$ stretching; respectively.
The three end peaks are related to the $\mathrm{C}-\mathrm{H}$ bending. The changes in the peak intensities and shifting are important to confirm the acid molecules and polymer chains' complex formation. A significant change is observed for the $\mathrm{O}-\mathrm{H}$ and $\mathrm{C}-\mathrm{O}$ stretching vibrations. The peak at $2780 \mathrm{~cm}^{-1}$ and other peak frequencies for $\mathrm{O}-\mathrm{H}$ and $\mathrm{C}-\mathrm{O}$ groups are observed in the gel electrolyte. In the gel electrolyte, the intensity of the stretching vibration of $\mathrm{O}-\mathrm{H}$ and $\mathrm{C}-\mathrm{O}$ peaks decreases, and the red-shift in the spectra indicates complex formation. This clearly shows that the interaction between the acid and PVA arises from $\mathrm{O}-\mathrm{H}$ groups and $\mathrm{C}-\mathrm{O}$ groups of PVA chains. The shifts in wavenumber observed for the gel electrolyte compared to the pure PVA point out to the possible interactions between the proton from $\mathrm{H}_{3} \mathrm{PO}_{4}$ with the polar groups of PVA. The proton ions can hop via each oxygen site of the PVA chains contributing to the conductivity $[18,25,26]$.

UV-Vis absorption spectra of aqueous PVA and GPEs are shown in Fig. 2 [24]. A major absorption peak at $194 \mathrm{~nm}$ and a shoulder at $259 \mathrm{~nm}$ are seen for pure PVA, attributed to the $n \rightarrow \pi^{*}$ transition of the hydroxyl group and $\pi \rightarrow \pi^{*}$ transition of unsaturated $C=C$ in the polymer chains. This transition from the ground state to a higher energy state corresponds to an electron's excitation from one of the unshared pairs to the $\pi^{*}$ orbital. The absorption peak at $194 \mathrm{~nm}$ has shifted to $192 \mathrm{~nm}$ for the gel electrolyte. This blue shift may be attributed to the decrease of hydrogen bonding between PVA chains and
Fig. 1 FTIR spectra of pure PVA and $\mathrm{PVA} / \mathrm{H}_{3} \mathrm{PO}_{4}$ gel electrolyte film $(\mathrm{Mw}=195,000 \mathrm{~g} / \mathrm{mole}$, $\left.\mathrm{PVA} / \mathrm{H}_{3} \mathrm{PO}_{4}(\mathrm{w} / \mathrm{w}) ; 1 / 2\right)[24]$

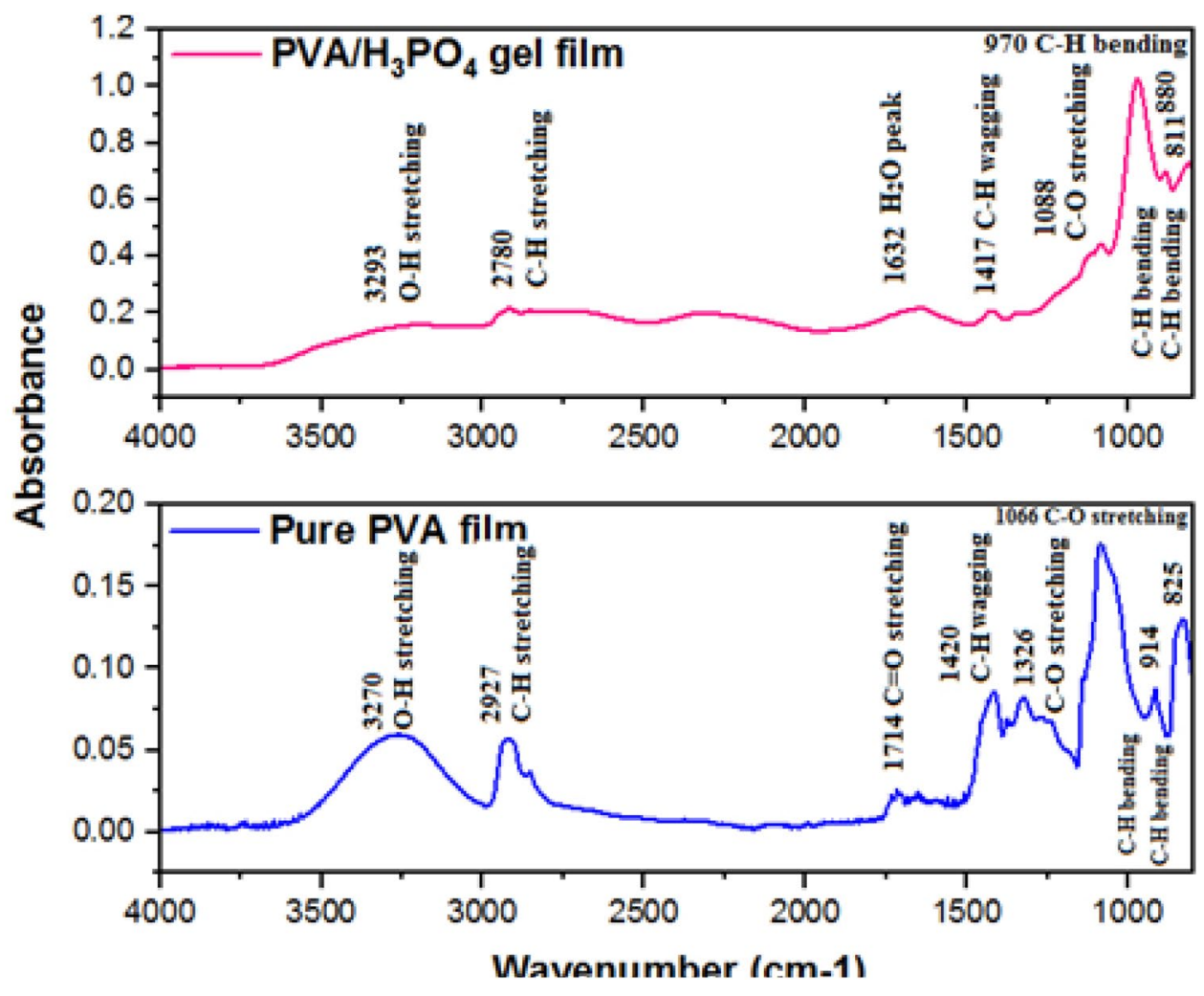



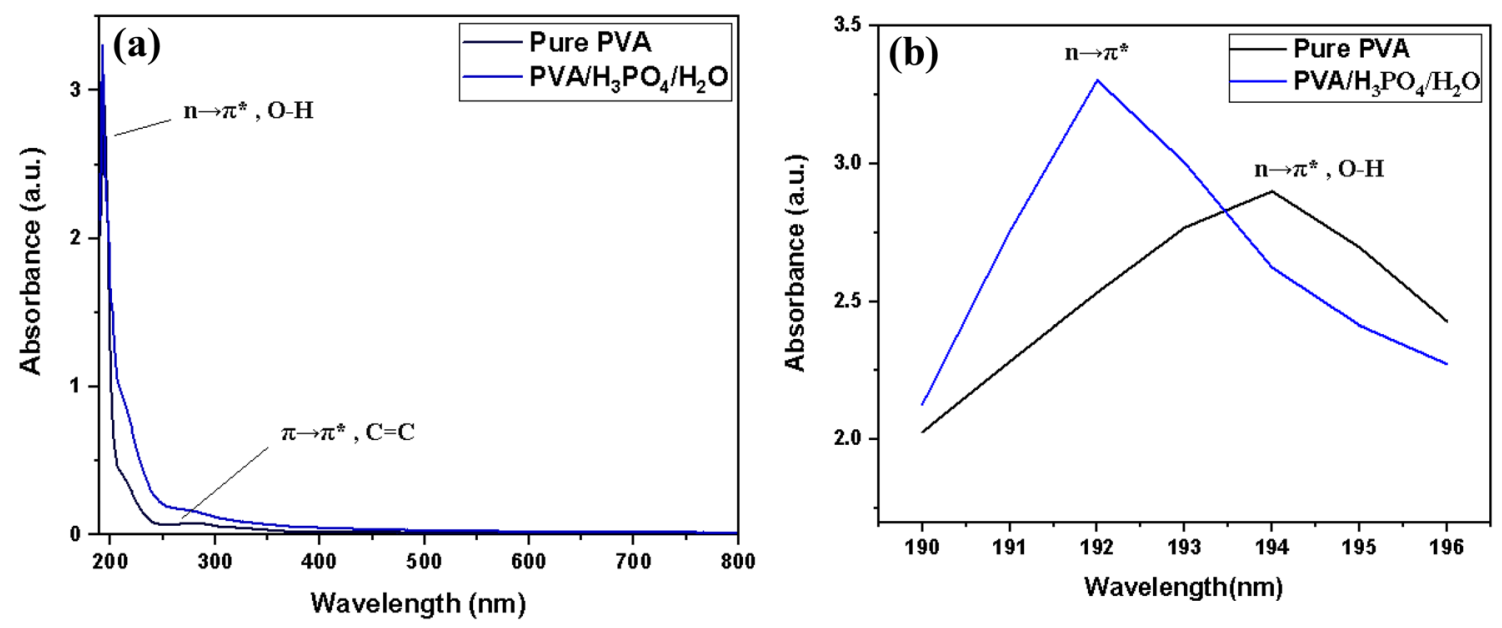

Fig. 2 UV-Vis absorption spectra of (a) pure PVA and $\mathrm{PVA} / \mathrm{H}_{3} \mathrm{PO}_{4} / \mathrm{H} 2 \mathrm{O}$ gel electrolyte aqueous solution $\left(\mathrm{Mw}=195,000 \mathrm{~g} / \mathrm{mole}, \mathrm{PVA} / \mathrm{H}_{3} \mathrm{PO} 4\right.$ $(\mathrm{w} / \mathrm{w}) ; 1 / 2),(\mathbf{b})$ The mentioned samples in (a) for small wavelength (190-196 nm) [24]

possible interactions between the proton from $\mathrm{H}_{3} \mathrm{PO}_{4}$ with the polar groups of PVA. Hence, the results indicate the complexation of the PVA by acid molecules [27].

GPEs have crystalline and amorphous phases stemming from pure polymer crystalline/amorphous phase and rich crystalline phase containing salt. It has been reported that many polymers have both crystalline and amorphous phases $[28,29]$. When salt or acid is added, they interact with the crystalline or amorphous polymer phases and change its properties. XRD is one of the most useful techniques to study the structural information of the gel electrolyte. XRD patterns of pure PVA film with a molecular weight of $195,000 \mathrm{~g} / \mathrm{mole}$ and gel electrolyte film are given in Fig. 3 [24]. The diffraction peaks of PVA appeared at $2 \theta$ values of $9.9^{\circ}$ and $19.5^{\circ}$. The broad peak at $9.9^{\circ}$ is attributed to the $d$-spacing of $8.8 \AA$ and the reflection plane of (110) while the other peak at $19.5^{\circ}$ corresponds to the d-spacing of $4.4 \AA$ and the reflection plane of (101), indicating the semi-crystalline nature of PVA. The intensity of (110) diffraction peak is higher because of hydroxyl groups in its side chains resulting in a high degree of hydrogen bonding [30,31]. This peak became less prominent in the gel and slightly broadened by the addition of $\mathrm{H}_{3} \mathrm{PO}_{4}$, probably due to the disruption of the crystalline phase of the PVA. There is a reduction in PVA crystallinity from 15 to $14 \%$ by the addition of $\mathrm{H}_{3} \mathrm{PO}_{4}$. Previous research shows that acid or salt's addition decreases the intensity of the diffraction peak of the polymer and simultaneously increases its amorphous nature. Therefore, the XRD pattern confirms the formation of the complexes of $\mathrm{H}_{3} \mathrm{PO}_{4}$ and PVA. The segmental motion of polymer chains is much higher in the amorphous phase facilitating ion mobility and causing higher ionic conductivity $[18,19,32]$.

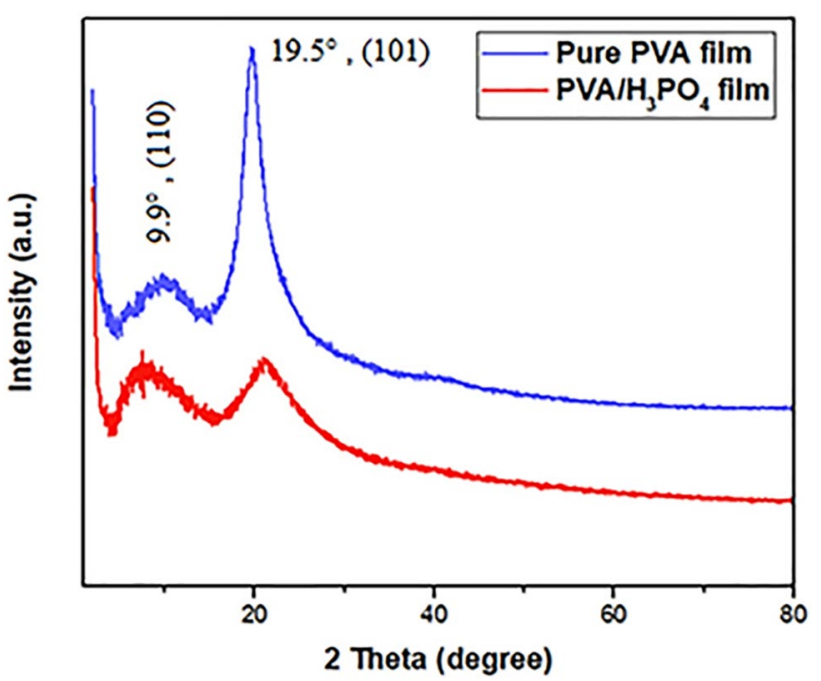

Fig. 3 X-ray diffraction pattern of pure PVA and $\mathrm{PVA} / \mathrm{H}_{3} \mathrm{PO}_{4} / \mathrm{H} 2 \mathrm{O}$ gel electrolyte film $\left(\mathrm{Mw}=19,500 \mathrm{~g} / \mathrm{mole}, \mathrm{PVA} / \mathrm{H}_{3} \mathrm{PO}_{4}(\mathrm{w} / \mathrm{w}) ; 1 / 2\right)$ [24]

The pure PVA film's morphologies, $\mathrm{PVA} / \mathrm{H}_{3} \mathrm{PO}_{4} / \mathrm{H} 2 \mathrm{O}$ gel electrolyte, are shown in SEM micrographs (Fig. 4) [24]. The pure PVA micrograph indicates pores, cracks, or droplets. Adding $\mathrm{H}_{3} \mathrm{PO}_{4}$ renders good structural integrity, smoothness, flatness with no phase separation and formation of a homogeneous film, confirming the enhancement of the amorphous phase due to the interaction between phosphoric acid and polymer chains. Moreover, the addition of $\mathrm{H}_{3} \mathrm{PO}_{4}$ creates a large number of open voids that are essential for ionic conductivity, and an open porous structure provides enough and suitable channels for ion migration. 
(a)

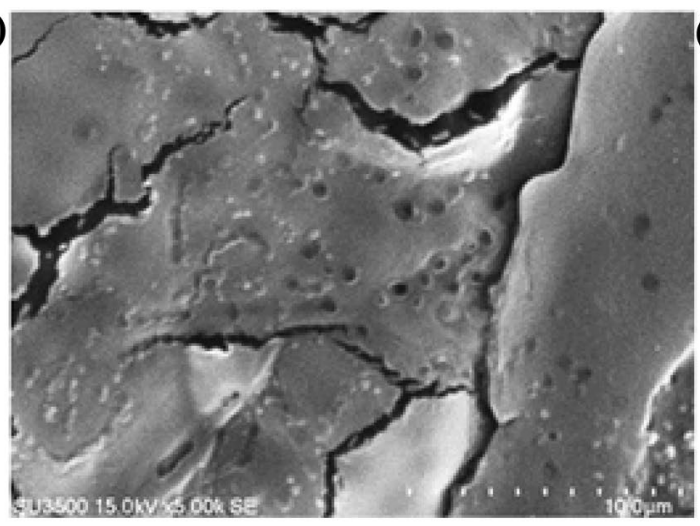

(b)

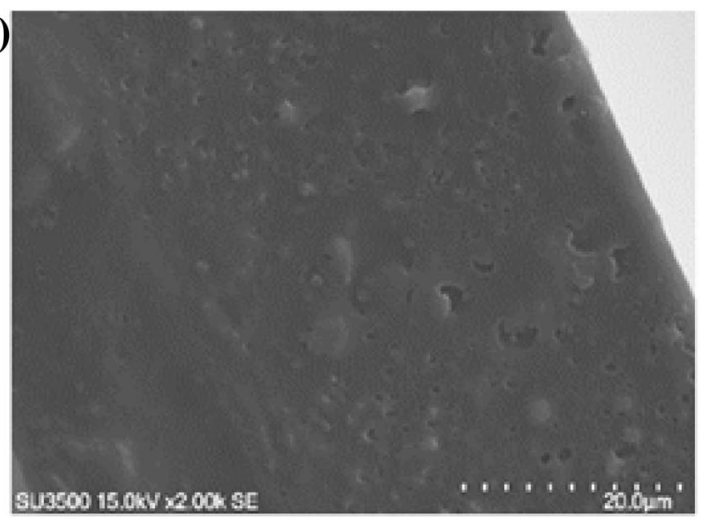

Fig. 4 SEM images of (a) pure PVA film (Mw=195,000 g/mole), (b) $\mathrm{PVA} / \mathrm{H}_{3} \mathrm{PO}_{4} / \mathrm{H} 2 \mathrm{O}$ gel film $\left(\mathrm{Mw}=195,000 \mathrm{~g} / \mathrm{mole} \mathrm{PVA} / \mathrm{H}_{3} \mathrm{PO}{ }_{4}(\mathrm{w} / \mathrm{w}) ; 1 / 2\right)$ [24]

\subsection{Conductivity characterization}

The total conductivity of the electrolyte solutions for different concentrations of $\mathrm{H}_{3} \mathrm{PO}_{4}$ was determined by a conductivity meter. In the first step, the effect of $\mathrm{H}_{3} \mathrm{PO}_{4}$ concentration on the total conductivity of the electrolytes for each molecular weight of PVA was investigated. Then, the sample with the highest conductivity for each molecular weight was chosen for studying the effect of PVA concentration on the total conductivity of electrolytes. It was found that as the solvent evaporates, polymer chains start forming gel film. It has been found that stretchable gel films can be obtained only from the solutions with a low concentration of $\mathrm{H}_{3} \mathrm{PO}_{4}$, e.g. $0.049,0.095 \mathrm{~g} / \mathrm{mL}\left(\mathrm{PVA} / \mathrm{H}_{3} \mathrm{PO}_{4}\right.$ weight ratio of $1 / 0.5$ and $1 / 1)$ for each molecular weight. For the highest molecular weight of PVA $(195,000 \mathrm{~g} /$ mole), acid concentration was $0.180 \mathrm{~g} / \mathrm{mL}\left(\mathrm{PVA} / \mathrm{H}_{3} \mathrm{PO}_{4}\right.$ weight ratio of 1/2). At the higher concentrations of $\mathrm{H}_{3} \mathrm{PO}_{4}$, the free volume of polymer chains increases, leading to the higher mobility of polymer segments than the low molecular weight PVA. Therefore, at a high acid/polymer ratio, the chains in low molecular weight do not contact with each other and cannot form a mechanically robust film. However, in PVA with higher molecular weight, the chains overlap or entangle with each other forming a flexible film. In other words, the aggregation of PVA chains occurs before the sol-gel transition, and the clusters are connected at the gel point resulting in the formation of a 3D-network structure. In the sample with high molecular weight, the probability of chain percolation (gelation) occurs at a lower concentration or the sol-gel transition concentration is inversely proportional to the polymer's molecular weight of the. According to the water content results (Fi@@gure S1-S9), the higher molecular weight with an acid concentration of $0.180 \mathrm{~g} / \mathrm{mL}\left(\mathrm{PVA} / \mathrm{H}_{3} \mathrm{PO}_{4}\right.$ weight ratio of $1 / 2$ ) retains more water (19\%) probably due to more entanglements between the polymer chains and also higher physical interactions between the solvent molecules, acid and polymer chains [23, 33, 34]. Therefore, the effect of $\mathrm{H}_{3} \mathrm{PO}_{4}$ and PVA concentration and molecular weight on the total conductivity of the electrolyte solutions are shown in Fig. 5. The dissociation constant for phosphoric acid in water is $7.5 \times 10^{-3}$, at $25^{\circ} \mathrm{C}$. The following equation determined proton concentration of each sample at equilibrium condition:

$\mathrm{Ka}=\left[\mathrm{H}_{3} \mathrm{O}^{+}\right]\left[\mathrm{H}_{2} \mathrm{PO}_{4}^{-}\right] /\left[\mathrm{H}_{3} \mathrm{PO}_{4}\right]$

The proton concentration and $\mathrm{pH}$ of each sample for different $\mathrm{H}_{3} \mathrm{PO}_{4}$ concentrations are tabulated in Ta@@ble S1 [35]. Figure 5a shows the addition of PVA decreases the total conductivity $\mathrm{H}_{3} \mathrm{PO}_{4}$ electrolyte solutions since it increases the viscosity of electrolyte and reduces the mobility of charge carriers. Beginning from the low concentration of $\mathrm{H}_{3} \mathrm{PO}_{4}$, total conductivity rises to a maximum at the concentration of $0.66 \mathrm{~g} / \mathrm{mL}\left(\mathrm{PVA} / \mathrm{H}_{3} \mathrm{PO}_{4}\right.$ weight ratio of $1 / 10)$, for all PVA molecular weights. Higher dissociation of $\mathrm{H}_{3} \mathrm{PO}_{4}$ provides more free ions as charge carries to contribute to higher total conductivity. However, this trend cannot be explained only increasing in the number of free ions with increasing $\mathrm{H}_{3} \mathrm{PO}_{4}$ content. Other factors such as higher ion mobility by water and polymer chains that take part through proton hopping via oxygen sites may increase ionic conductivity. With a further increase in $\mathrm{H}_{3} \mathrm{PO}_{4}$ concentration, total conductivity reaches a maximum value and then shows a decrease, which is probably due to the suppression of ion dissociation at high $\mathrm{H}_{3} \mathrm{PO}_{4}$ concentration. This is attributed to the presence of ion aggregates that do not take part in the conduction process, and an increase in viscosity, causing lower conductivity. The carrier mobility of ions is significantly affected 

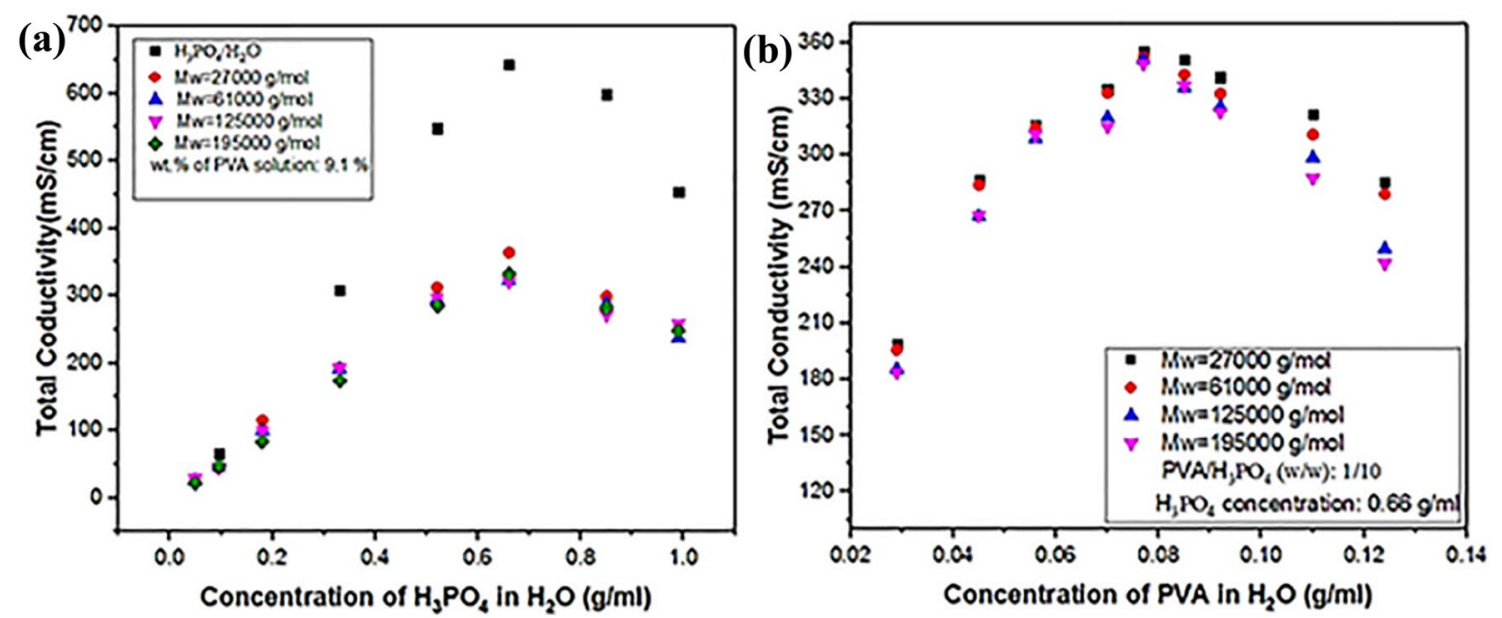

Fig. 5 The total conductivity results versus concentration of a) $\mathrm{H}_{3} \mathrm{PO}_{4}$ and b) PVA in $\mathrm{H}_{2} \mathrm{O}$ for different Mw of PVA (The total conductivity for each molecular weight at PVA and $\mathrm{H}_{3} \mathrm{PO}_{4}$ constant concentration are given in $\mathrm{SI}$ )

by the segmental motion of the polymer chains. In a high amount of $\mathrm{H}_{3} \mathrm{PO}_{4}$, the ion aggregates may decrease the polymer chains' segmental motion, which may reduce the total conductivity [36-40]. The effect of PVA concentration on the total conductivity of gel electrolyte solutions with optimum concentration of $\mathrm{H}_{3} \mathrm{PO}_{4}(0.66 \mathrm{~g} / \mathrm{mL})$ is shown in Fig. 5b. An enhancement in the total conductivity of gel electrolytes at low polymer concentration can be explained by the" Breathing polymeric chain model" which is schematically shown in Fig. 6. According to this model and previous studies, a gel electrolyte is composed of polymer chains (folded or partially/fully unfolded chains), solvent and dissociate ions or ion aggregates. At low concentrations of PVA, the gel electrolyte behaves as a liquid electrolyte. The breathing of the polymer chains by the folding of its chains causes a density or pressure fluctuation, which can help dissociate ion aggregates and assist the motion of ions. In this model, polymer chains participate in the charge transfer process, which may contribute to the higher total conductivity [41-43]. According to the Arrhenius theory of electrolyte dissociation, there is a dynamic equilibrium between ions and molecules. It was explained by Ostwald law that like chemical equilibrium law of mass that can also be applied to such systems. This phenomenon also could be explained by Ostwald's dilution law, which is a relationship between the dissociation constant (Kd), degree of dissociation (a), the total concentration of electrolyte $(\mathrm{CO})$, and concentration of anyone ionic species for a weak electrolyte. By increasing the PVA concentration since the weight ratio of $\mathrm{PVA} / \mathrm{H}_{3} \mathrm{PO}_{4}$ is constant, the $\mathrm{C} 0$ increases at a constant temperature leading to the high concentration of ions in the electrolyte and results in high ionic conductivity. At a high concentration of PVA, gel electrolyte's viscosity becomes the dominant factor and decreases the mobility of ions and, hence, the total conductivity [41-43].

Therefore, Fig. 5 demonstrate that the total conductivity is a function of the concentration of $\mathrm{H}_{3} \mathrm{PO}_{4}$ and $\mathrm{PVA}$, and has an optimum value. lons from the dissociation of $\mathrm{H}_{3} \mathrm{PO}_{4}$ determine the concentration of charge carriers. At the same time, PVA may increase ion's mobility or create channels for ion transfer or decrease by increasing viscosity. This can be explained and verified by applying the De Gennes theory [44] to determine the size of PVA channels. In a dilute polymer solution, polymer coils do not attract one another while, in a concentrated polymer solution, the coils are overlapped. Between these two regimes, i.e., at the overlap threshold $\left(C=C^{*}\right)$, the polymer coils begin to touch one another.

$C^{*} \sim N / R^{3}$

$\mathrm{N}$ is the degree of polymerization, and $\mathrm{R}$ is the spherical radius of the polymer coil.

In this region, the volume fraction of the polymer is given by the following formula:

$\Phi^{* \sim N}-0.8$

It should be noted that the PVA concentration of all of our samples is higher than the threshold concentration $\left(C>C^{*}\right)$ and $\Phi^{*}<<\Phi<<1$ (Table S2). Hence, the mesh size (the space between macromolecular chains, which is used for ion transfer) of PVA channels is calculated by the following equation:

$\xi \cong a . \Phi-0.75$

This suggests that the size of channels does not depend on the molecular weight of the polymer. Figure S10. In 
Fig. 6 "Breathing polymeric chain model" for gel polymer electrolyte for $C<C^{*}$. The volume is occupied by polymeric chains in a liquid electrolyte containing ions from the dissolved acid at different times $[41,44]$
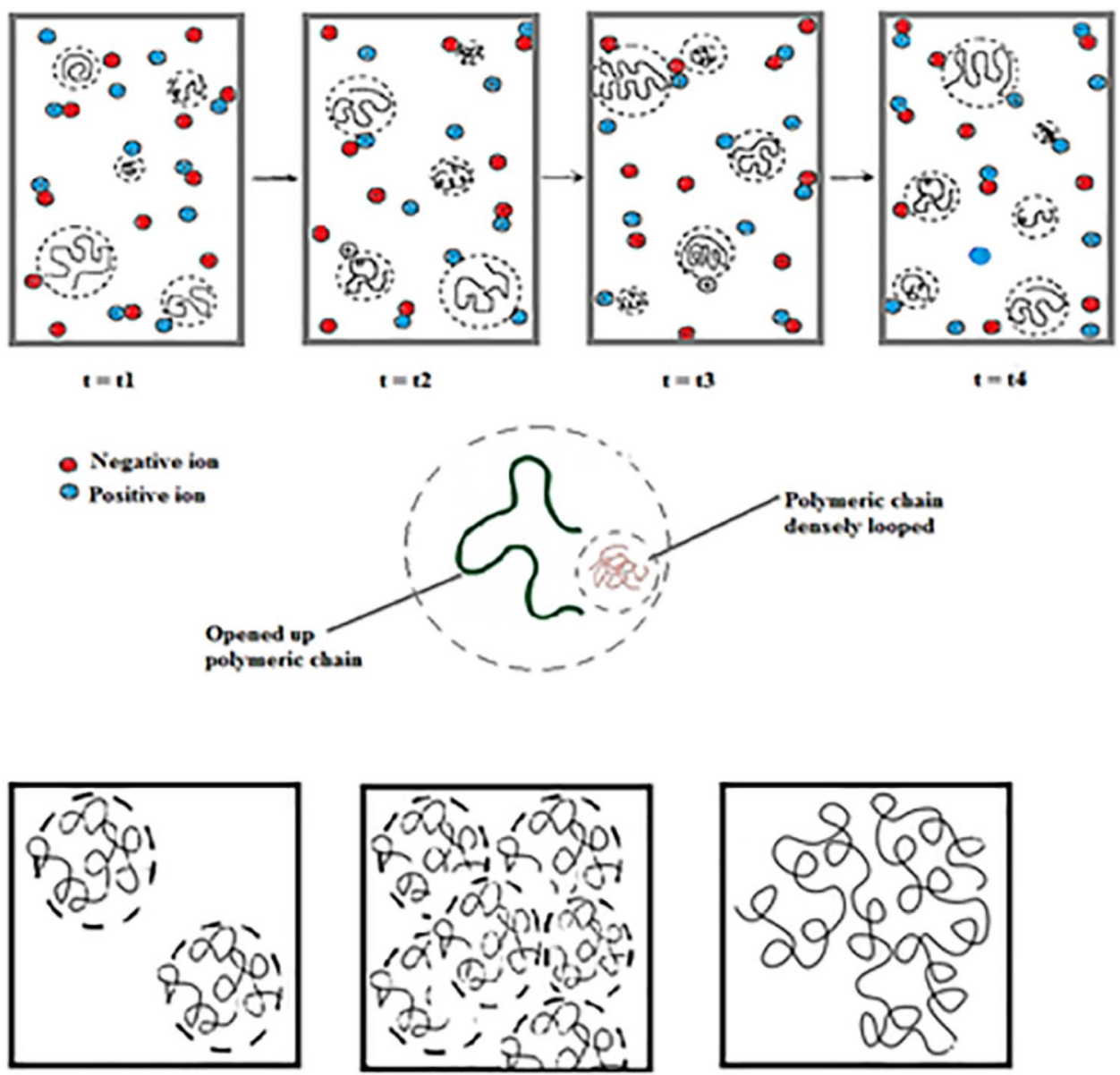

$\mathrm{C}<\mathrm{C}^{*}$

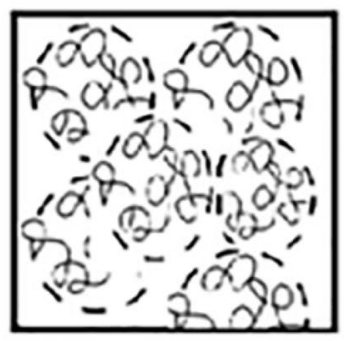

$\mathbf{C}=\mathbf{C}^{\star}$

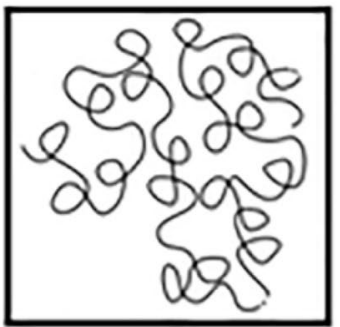

$\mathrm{C}>\mathrm{C}^{*}$
Table 1 The degree of polymerization and the approximate amount of $C^{*}$ and $\Phi^{*}$ of PVA with different molecular weights [44]

\begin{tabular}{lrl}
\hline Mw $(\mathrm{g} /$ mole $)$ & $\mathrm{N}$ & $\mathrm{C}^{*}(\mathrm{wt} \%)$ \\
\hline 27,000 & 613.636 & 2.812 \\
61,000 & 1386.364 & 1.465 \\
125,000 & 2840.909 & 0.825 \\
195,000 & 4431.818 & 0.578 \\
\hline
\end{tabular}

supporting information shows that at a constant concentration of acid the mesh size increases by decreasing the PVA concentration, which may be attributed to higher water content and lower hydrogen bonding between polymer chains. (Table 1).

The ionic conductivity of the gel electrolytes was investigated by electrochemical impedance spectroscopy (EIS). The results of the EIS test for $\mathrm{H}_{3} \mathrm{PO}_{4}$ concentration of 0.049 and $0.095 \mathrm{~g} / \mathrm{mL}\left(\mathrm{PVA} / \mathrm{H}_{3} \mathrm{PO}_{4}\right.$ weight ratio of $1 / 0.5$ and $1 / 1$ ) for each $M w$ and $0.180 \mathrm{~g} / \mathrm{mL}$ (PVA $/ \mathrm{H}_{3} \mathrm{PO}_{4}$ weight ratio of $1 / 2$ ) for $195,000 \mathrm{~g} / \mathrm{mol}$ are shown in Fig. 7 a, b, c respectively. Figure 6 means that gel film's resistance behavior with a non-zero intersect in the high-frequency region and the capacitive behaviour in the low-frequency region with a straight line [45]. The figure's intersection shows the analysis result of impedance spectra with Zsim software based on the electrical equivalent circuit. Ohmic resistance $(R)$ of the electrolyte, and constant phase element $(\mathrm{Q})$ of the double layer could be obtained using the software. Ionic conductivity of gel electrolytes is calculated based on the value of ohmic resistance. Therefore, the fitted data for R-value are presented in Table 2. The ionic conductivity of the GPEs was calculated based on the Eqs. 2, 3 that it is shown in Table 3. Where $L$ is the thickness of the film $(400-500 \mu \mathrm{m}), \mathrm{R}$ is the ohmic resistance of electrolyte (ohm), and A is the contact area of electrolyte film with stainless steel electrodes during the test $\left(1 \mathrm{~cm}^{2}\right)$. Additionally, the ionic conductivity of a gel electrolyte depends on the concentration of charge carriers ( $n$ ) and carrier mobility $(\mu)$ [46-48].

$\sigma=n q \mu$

In which $q$ is the charge of mobile carriers. 

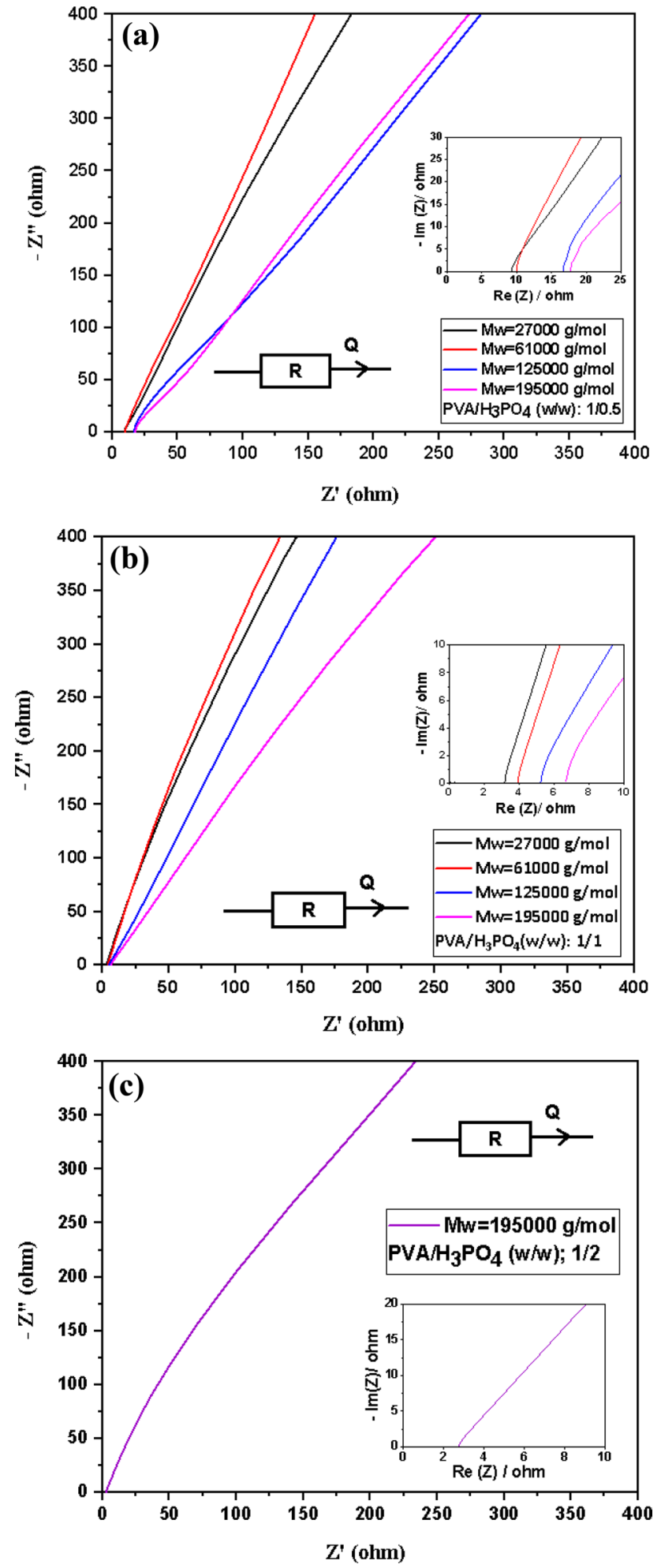

Fig. 7 Nyquist plots of $\mathrm{PVA} / \mathrm{H}_{3} \mathrm{PO}_{4} / \mathrm{H} 2 \mathrm{O}$ gel electrolyte films at different molecular weights of PVA for the various weight ratio of PVA/ $\mathrm{H}_{3} \mathrm{PO}_{4}$ as, (a) $1 / 0.5$, (b) $1 / 1$ and (c) $1 / 2$ for $\mathrm{Mw}=195,000 \mathrm{~g} / \mathrm{mole}$
Figure 7 and Table 2 indicate that by increasing the PVA molecular weight at a constant weight ratio to $\mathrm{H}_{3} \mathrm{PO}_{4}$, the physical interaction between polymer chains and bulk resistance of the gel electrolyte is increased [49]. Although the high molecular weight relates to high viscosity, the free end of chains and free volume of the polymer are decreased, resulting in low ionic motion, which leads to a decrease in ionic conductivity. Moreover, by increasing the amount of phosphoric acid (charge carriers) in gel electrolytes for each $\mathrm{Mw}$, the bulk resistance is reduced, and ionic conductivity increases. This can be attributed to the increased number of charge carrier $\left(\mathrm{H}_{3} \mathrm{O}^{+}\right)$ions produced by $\mathrm{H}_{3} \mathrm{PO}_{4}$. A few reports in the literature on ionic conductivity of gel electrolytes are based on PVA and H3PO4. Thus, a complete comparison for multiple component systems is given in Ta@@ble S3, which considered the effect of different additives such as nanoparticles, ionic liquids, and plasticizers on the PVA-based gel's ionic conductivity of. It can be seen that the amount of acid has a significant effect on ionic conductivity, which also investigated in this work.

The higher amount of dissociated acid leads to higher mobile free ions resulting in high ionic conductivity. To the best of our knowledge, no report on the study, the effect of PVA molecular weight on ionic conductivity has been published, yet. Table 3 shows the ionic conductivity of different gel electrolytes based on PVA for simple ternary systems. High molecular weight results in high viscosity and in lower mobility of ions and ionic conductivity. PVA with low molecular weight has a more segmental motion that helps increase ion mobility $[6,48]$.

Furthermore, we showed that the gel electrolyte with various PVA molecular weight has a different amount of water in the gel structure. PVA with high molecular weight has more chain entanglements, holding more water molecules. The higher value of water molecules leads to a more considerable amount of dissociated free ions, which results in high ionic conductivity $[17,18,21,38,48,50]$. The ionic conductivity of the gel electrolyte in our work is appreciably high $\left(14.75 \pm 1.39 \mathrm{mS} \mathrm{cm}^{-1}\right)$ compared with other reported gel electrolytes due to the high amount of acid and water in the gel. However, some articles are not comparable with present work in terms of not reporting the PVA's molecular weight and the amount of water.

\subsection{Mechanical properties and cycle life}

The mechanical properties of pure PVA film and PVA$\mathrm{H}_{3} \mathrm{PO}_{4}-\mathrm{H}_{2} \mathrm{O}$ based on gel electrolytes for various molecular weights of PVA and $\mathrm{PVA} / \mathrm{H}_{3} \mathrm{PO}_{4}$ weight ratio of $1 / 0.5$, $1 / 1$ are shown in Fig. 8. PVA is a semi-crystalline polymer containing crystalline layers and amorphous folded chains with a higher tensile strength $(72.04 \pm 10.60 \mathrm{MPa})$ 
Table 2 lonic conductivity of $\mathrm{PVA} / \mathrm{H}_{3} \mathrm{PO}_{4} / \mathrm{H} 2 \mathrm{O}$ gel polymer electrolytes

\begin{tabular}{lllcr}
\hline $\begin{array}{l}\text { The molecular weight } \\
\text { of PVA (g/mole) }\end{array}$ & $\begin{array}{l}\text { PVA/H3PO4 } \\
\text { weight ratio }\end{array}$ & $\begin{array}{l}\text { The thickness of the } \\
\text { electrolyte film }(\mu \mathrm{m})\end{array}$ & $\begin{array}{l}\text { Bulk resistance of the } \\
\text { electrolyte (ohm) }\end{array}$ & $\begin{array}{r}\text { lonic conduc- } \\
\text { tivity (mS/cm) }\end{array}$ \\
\hline 27,000 & $1 / 0.5$ & $14 \pm 437$ & $27.0 \pm 42.9$ & $18.0 \pm 76.4$ \\
27,000 & $1 / 1$ & $405 \pm 7$ & $3.06 \pm 0.14$ & $13.26 \pm 0.84$ \\
61,000 & $1 / 0.5$ & $442 \pm 11$ & $10.19 \pm 0.30$ & $4.38 \pm 0.18$ \\
61,000 & $1 / 1$ & $412 \pm 9$ & $3.99 \pm 0.13$ & $10.32 \pm 0.09$ \\
125,000 & $1 / 0.5$ & $469 \pm 9$ & $16.65 \pm 0.07$ & $2.82 \pm 0.06$ \\
125,000 & $1 / 1$ & $416 \pm 9$ & $5.60 \pm 0.54$ & $7046 \pm 0.55$ \\
195,000 & $1 / 0.5$ & $443 \pm 5$ & $17.70 \pm 0.28$ & $2.50 \pm 0.07$ \\
195,000 & $1 / 1$ & $419 \pm 6$ & $6.45 \pm 0.32$ & $6.51 \pm 0.23$ \\
195,000 & $1 / 2$ & $406 \pm 6$ & $2.77 \pm 0.22$ & $14.75 \pm 1.39$ \\
\hline
\end{tabular}

Table 3 Comparison of ionic conductivity of gel electrolytes based on PVA for simple ternary systems with different reported value

\begin{tabular}{lllll}
\hline Electrolyte & $\begin{array}{l}\text { Molecular weight(Mw) } \\
\text { of PVA (g/mole) }\end{array}$ & $\begin{array}{l}\text { Weight ratio }(w / w) \text { of } \\
\text { PVA: H3PO4 }\end{array}$ & $\begin{array}{l}\text { lonic conductivity } \\
\left(\mathrm{mS} \mathrm{cm}^{-1}\right)\end{array}$ & Ref \\
\hline $\mathrm{PVA} / \mathrm{H}_{3} \mathrm{PO}_{4} / \mathrm{H}_{2} \mathrm{O}$ & $124,000-186,000$ & $1: 1$ & 0.96 & {$[23]$} \\
& & $1: 1.5$ & 3.44 & {$[51]$} \\
$\mathrm{PVA} / \mathrm{H}_{3} \mathrm{PO}_{4} / \mathrm{H}_{2} \mathrm{O}$ & 95,000 & $1: 0.8$ & 0.056 & {$[18]$} \\
$\mathrm{PVA} / \mathrm{H}_{3} \mathrm{PO}_{4} / \mathrm{H}_{2} \mathrm{O}$ & 125,000 & $1: 0.4$ & 0.00152 & {$[52]$} \\
$\mathrm{PVA} / \mathrm{H}_{3} \mathrm{PO}_{4} / \mathrm{H}_{2} \mathrm{O}$ & 130,000 & $1: 0.8$ & 0.78 & {$[16]$} \\
$\mathrm{PVA} / \mathrm{H}_{3} \mathrm{PO}_{4} / \mathrm{H}_{2} \mathrm{O}$ & $\ldots$ & $1: 2$ & 11.58 & {$[27]$} \\
$\mathrm{PVA} / \mathrm{H}_{2} \mathrm{SO}_{4} / \mathrm{H}_{2} \mathrm{O}$ & $\ldots$ & $1: 1$ & 7.1 & {$[30]$} \\
$\mathrm{PVA} / \mathrm{H}_{3} \mathrm{PO}_{4} / \mathrm{H}_{2} \mathrm{O}$ & 98,000 & $1: 2$ & 2.56 & {$[53]$} \\
$\mathrm{PVA} / \mathrm{H}_{2} \mathrm{SO}_{4} / \mathrm{H}_{2} \mathrm{O}$ & $\ldots$ & $1: 2$ & 11.4 & This work \\
$\mathrm{PVA} / \mathrm{H}_{3} \mathrm{PO}_{4} / \mathrm{H}_{2} \mathrm{O}$ & 195,000 & $1: 2$ & $14.75 \pm 1.39$ &
\end{tabular}

compared to the electrolyte specimens. At lower molecular weights, tensile strength and elastic modulus are lower for the gel electrolytes due to more chains or chains with a shorter length that form crystalline layers. Hence, they can easily slip as exposed to stress. In other words, the free end of chains act as a defect in the system and reduce the mechanical strength and elastic modulus. Elongation at break of the gel electrolyte samples is higher than the pure PVA film (124.09 $\pm 4.21 \%)$ due to phosphoric acid. The bonds between polymer chains are weakened by phosphoric acid at the molecular level. At the same time, the free volume or inter-chain spaces are increased, making the polymer chains more flexible $[23,54]$. As seen in Fig. 8 , the elastic modulus and tensile strength of the electrolyte are decreased by increasing the amount of phosphoric acid while the elongation at break increased. Due to the presence of phosphoric acid, the amorphous polymer content increased, and its crystallinity decreased, making the electrolyte film more flexible, which is consistent with the results of characterization tests. The mechanical properties of the gel electrolyte with the $\mathrm{Mw}$ of $195,000 \mathrm{~g} / \mathrm{mole}$ and $\mathrm{PVA} / \mathrm{H}_{3} \mathrm{PO}_{4}$ weight ratio of $1 / 2$ are also given in Fig. $8 \mathrm{c}$ [24].

In comparison with other gel electrolytes, this sample has a higher elongation at break (766.66 $\pm 59.73 \%)$ and less elastic modulus ( $1.51 \pm 0.21 \mathrm{MPa})$ and tensile strength $(4.75 \pm 0.21 \mathrm{MPa})$ due to its higher content of phosphoric acid. As mentioned before, the molecules of phosphoric acid can easily enter into the space between polymer chains and reduce the interactions between them, leading to more flexible chains with more segmental motion. In this way, the polymer matrix becomes capable of tolerating a large deformation before failure. The surface area below the stress-strain curve is known as toughness or the specimen's resistivity under the crack propagation, which is enhanced by increasing phosphoric acid amount $[23,54,55]$. The results of the mechanical properties are summarized in Ta@@ble S4. Cyclic stability of the stretchable gel electrolyte was assessed at a current density of $1 \mu \mathrm{A} \mathrm{g}^{-1}$ for 2000 cycles (Fig. 8(d)). After 2000 charge-discharge cycles, the Cs (calculated based on Eq. 5) of the PVA/ $\mathrm{H}_{3} \mathrm{PO}_{4} / \mathrm{H} 2 \mathrm{O}$ gel electrolyte decreases from 140 to about $100 \mu \mathrm{F} . \mathrm{g}-1$. The stretchable gel retains $70 \%$ of initial capacitance after 2000 cycles. Thus, the gel electrolyte based on Mw of $195,000 \mathrm{~g} / \mathrm{mole}$ and PVA/H3PO4 (w/w): 1/2 indicates the highest ionic conductivity and elasticity are promising candidates for the fabrication of flexible and wearable gadgets. 

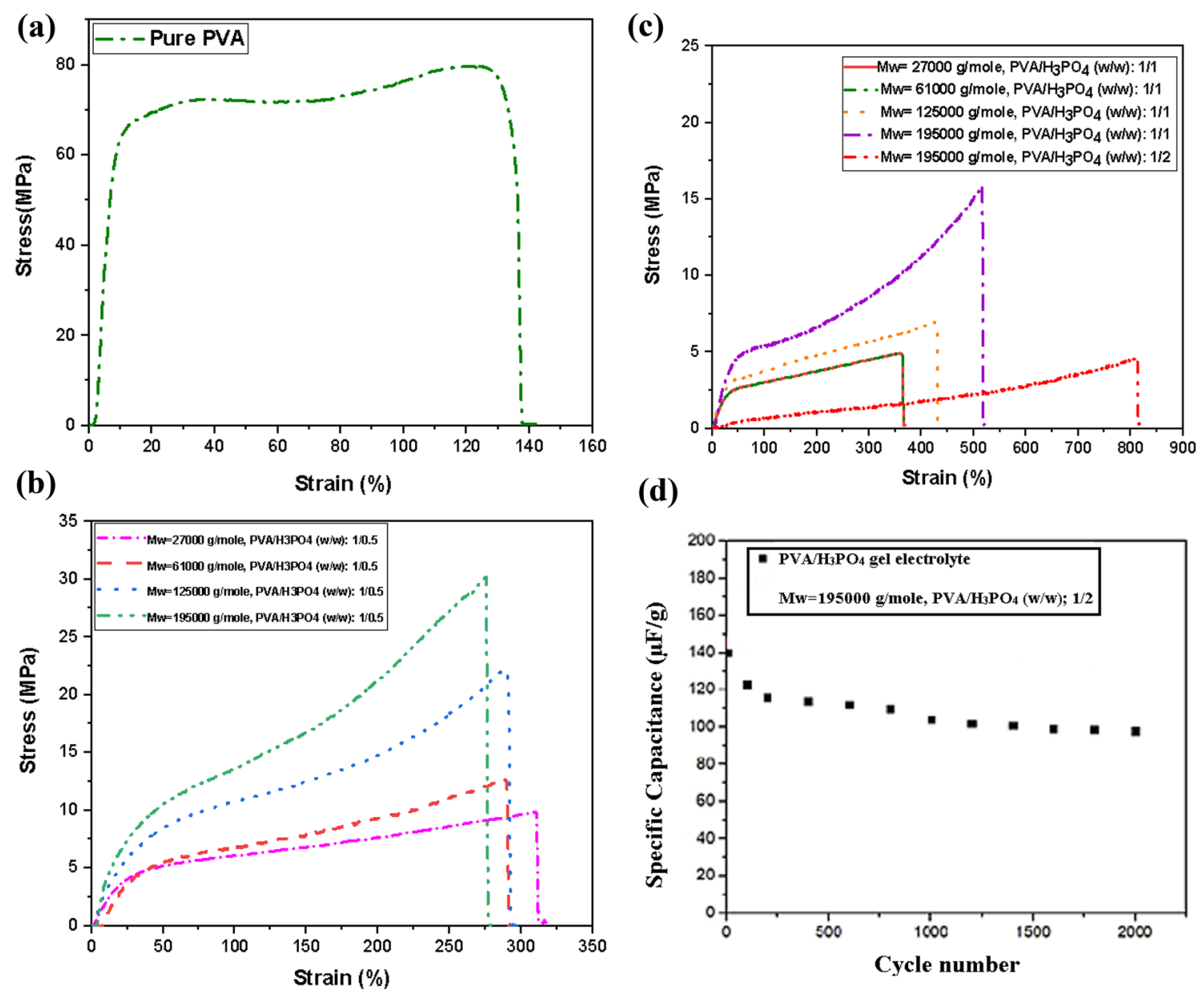

Fig. 8 Stress-strain curve for (a) Pure PVA film, (b) PVA $/ \mathrm{H}_{3} \mathrm{PO}_{4} / \mathrm{H} 2 \mathrm{O}$ gel electrolyte films for $\mathrm{PVA} / \mathrm{H}_{3} \mathrm{PO}_{4}$ weight ratio of $1 / 0.5$, (c) $1 / 1$ at different molecular weights of PVA and $1 / 2$ for $M w=195,000 \mathrm{~g} /$

\section{Conclusions}

Gel polymer electrolytes based on $\mathrm{PVA} / \mathrm{H}_{3} \mathrm{PO}_{4} / \mathrm{H}_{2} \mathrm{O}$ were prepared by the solution casting method. The effect of PVA molecular weight and $\mathrm{PVA} / \mathrm{H}_{3} \mathrm{PO}_{4}$ weight ratio on ionic conductivity and mechanical properties were studied. It was found that there is an optimum $\mathrm{PVA} / \mathrm{H}_{3} \mathrm{PO}_{4}$ ratio that gives the highest total conductivity, regardless of PVA molecular weight. PVA molecular weight had a determining effect on the mechanical properties of the gel. Therefore, gel conductivity and mechanical properties can be tuned by the $\mathrm{PVA} / \mathrm{H}_{3} \mathrm{PO}_{4}$ ratio and PVA molecular weight. This deserves further study to see if it can be generalized to other polymeric electrolyte gels, by understanding the role that polymer plays. The gel electrolyte with a molecular weight of $195,000 \mathrm{~g} / \mathrm{mole}$ and $\mathrm{PVA} / \mathrm{H}_{3} \mathrm{PO}_{4}$ ratio of $1 / 2$ had the highest ionic conductivity $14.75 \pm 1.39 \mathrm{mS} \mathrm{cm}^{-1}$, with the best mechanical properties including the highest elongation at break (\%766.66 \pm 59.73$)$. Hence, it can be mole, c) Cycle life for $\mathrm{PVA} / \mathrm{H}_{3} \mathrm{PO}_{4} / \mathrm{H} 2 \mathrm{O}$ gel electrolyte film (PVA/ $\mathrm{H}_{3} \mathrm{PO}_{4}$ weight ratio $1 / 2, \mathrm{Mw}=195,000 \mathrm{~g} / \mathrm{mole}$ ) [24]

considered a highly promising candidate for flexible and wearable electronic gadgets and energy storage devices.

Acknowledgements This work was supported by the Department of Polymer Engineering \& Color Technology, Amirkabir University of Technology in Tehran, Iran and was partially supported by the Condensed Matter National Laboratory, Institute for Research in Fundamental Sciences (IPM) in Tehran, Iran. S.H.A. acknowledges the financial support from Pasargad Institute for Advanced Innovative Solutions (PIAIS) under the Supporting Grant scheme (Project SG1-RMS1705-01) and Equipment and Infrastructure Grant scheme (El1-MC1709-01).

Data availability All authors declare that the data supporting of this study are available within the article and its supplementary information files.

\section{Compliance with ethical standards}

Conflict of interest The authors declare that there is no conflict of interest in writing the paper and stating results. 
Open Access This article is licensed under a Creative Commons Attribution 4.0 International License, which permits use, sharing, adaptation, distribution and reproduction in any medium or format, as long as you give appropriate credit to the original author(s) and the source, provide a link to the Creative Commons licence, and indicate if changes were made. The images or other third party material in this article are included in the article's Creative Commons licence, unless indicated otherwise in a credit line to the material. If material is not included in the article's Creative Commons licence and your intended use is not permitted by statutory regulation or exceeds the permitted use, you will need to obtain permission directly from the copyright holder. To view a copy of this licence, visit http://creativecommons .org/licenses/by/4.0/.

\section{References}

1. Lu X, Yu M, Wang G, Tong Y, Li Y (2014) Flexible solid-state supercapacitors: design, fabrication and applications. Energy Environ Sci 7(7):2160-2181

2. Zhong C, Deng Y, Hu W, Qiao J, Zhang L, Zhang J (2015) A review of electrolyte materials and compositions for electrochemical supercapacitors. Chem Soc Rev 44(21):7484-7539

3. Alipoori S, Mazinani S, Aboutalebi SH, Sharif F (2020) Review of PVA-based gel polymer electrolytes in flexible solid-state supercapacitors: Opportunities and challenges. J Energy Storage 27:101072

4. Choudhury N, Sampath S, Shukla A (2009) Hydrogel-polymer electrolytes for electrochemical capacitors: an overview. Energy Environ Sci 2(1):55-67

5. Jagadeesan A, Sasikumar M, Jeevani R, Therese $H$, Ananth $N$, Sivakumar P (2019) Fabrication of BaTiO 3 ceramic filler incorporated PVC-PEMA based blend nanocomposite gel polymer electrolytes for Li ion battery applications. J Mater Sci Mater Electron 30(18):17181-17194

6. Aziz SB, Hamsan M, Brza M, Kadir M, Abdulwahid RT, Ghareeb HO, Woo H (2019) Fabrication of energy storage EDLC device based on CS: PEO polymer blend electrolytes with high $\mathrm{Li}+$ ion transference number. Results Phys 15:102584

7. Brza MA, Aziz SB, Nofal MM, Saeed SR, Al-Zangana S, Karim WO, Hussen SA, Abdulwahid RT, Kadir MF (2020) Drawbacks of low lattice energy ammonium salts for ion-conducting polymer electrolyte preparation: structural, morphological and electrical characteristics of CS: PEO: NH4BF4-based polymer blend electrolytes. Polymers 12(9):1885

8. Mustafa MS, Ghareeb HO, Aziz SB, Brza M, Al-Zangana S, Hadi JM, Kadir M (2020) Electrochemical characteristics of glycerolized peo-based polymer electrolytes. Membranes 10(6):116

9. Song J, Wang Y, Wan CC (1999) Review of gel-type polymer electrolytes for lithium-ion batteries. J Power Sour 77(2):183-197

10. Bhad SN, Sangawar V (2012) Synthesis and study of PVA based gel electrolyte. Chem Sci Trans 1(3):653-657

11. Yang $X$, Zhang F, Zhang L, Zhang T, Huang Y, Chen Y (2013) A high-performance graphene oxide-doped ion gel as gel polymer electrolyte for all-solid-state supercapacitor applications. Adv Func Mater 23(26):3353-3360

12. Aslam M, Kalyar MA, Raza ZA (2020) Fabrication of nano-CuOloaded PVA composite films with enhanced optomechanical properties. Polym Bull. https://doi.org/10.1007/s00289-02003173-9

13. Aslam M, Kalyar MA, Raza ZA (2018) Polyvinyl alcohol: a review of research status and use of polyvinyl alcohol based nanocomposites. Polym Eng Sci 58(12):2119-2132

14. Liu J, Song H, Wang Z, Zhang J, Zhang J, Ba X (2020) Stretchable, self-healable, and reprocessable chemical cross-linked ionogels electrolytes based on gelatin for flexible supercapacitors. J Mater Sci 55(9):3991-4004

15. Mishra K, Arif T, Kumar R, Kumar D (2019) Effect of Al2O3 nanoparticles on ionic conductivity of PVdF-HFP/PMMA blendbased $\mathrm{Na}$-ion conducting nanocomposite gel polymer electrolyte. J Solid State Electrochem 23(8):2401-2409

16. Sun K, Dong M, Feng E, Peng H, Ma G, Zhao G, Lei Z (2015) High performance solid state supercapacitor based on a 2-mercaptopyridine redox-mediated gel polymer. RSC Adv 5(29):22419-22425

17. Gao H, Lian K (2013) Effect of SiO2 on silicotungstic AcidH3PO4-poly (vinyl alcohol) electrolyte for electrochemical supercapacitors. J Electrochem Soc 160(3):A505-A510

18. Prajapati G, Roshan R, Gupta P (2010) Effect of plasticizer on ionic transport and dielectric properties of PVA-H3PO4 proton conducting polymeric electrolytes. J Phys Chem Sol 71(12):1717-1723

19. Pavani Y, Ravi M, Bhavani S, Sharma A, Narasimha Rao V (2012) Characterization of poly (vinyl alcohol)/potassium chloride polymer electrolytes for electrochemical cell applications. Polym Eng Sci 52(8): 168-169

20. Gao H, Lian K (2014) Proton-conducting polymer electrolytes and their applications in solid supercapacitors: a review. RSC Adv 4(62):33091-33113

21. Chen Q, Li X, Zang X, Cao Y, He Y, Li P, Wang K, Wei J, Wu D, Zhu $\mathrm{H}$ (2014) Effect of different gel electrolytes on graphene-based solid-state supercapacitors. RSC Adv 4(68):36253-36256

22. Analytical R (2004) Conductivity theory and practice. Radiometer Analytical SAS, France

23. Zhao C, Wang C, Yue Z, Shu K, Wallace GG (2013) Intrinsically stretchable supercapacitors composed of polypyrrole electrodes and highly stretchable gel electrolyte. ACS Appl Mater Interf 5(18):9008-9014

24. Alipoori S, Torkzadeh M, Moghadam MM, Mazinani S, Aboutalebi SH, Sharif F (2019) Graphene oxide: an effective ionic conductivity promoter for phosphoric acid-doped poly (vinyl alcohol) gel electrolytes. Polymer 184:121908

25. Stuart BH (2004) Infrared spectroscopy: fundamental and applications. Wiley. https://doi.org/10.1002/047001114

26. Aziz SB, Marif RB, Brza M, Hassan AN, Ahmad HA, Faidhalla YA, Kadir M (2019) Structural, thermal, morphological and optical properties of PEO filled with biosynthesized Ag nanoparticles: new insights to band gap study. Res Phys 13:102220

27. Mallakpour S, Abdolmaleki A, Borandeh S (2015) Surface functionalization of GO, preparation and characterization of PVA/ TRIS-GO nanocomposites. Polymer 81:140-150

28. Lobitz $\mathrm{P}$, Füllbier $\mathrm{H}$, Reiche $\mathrm{A}$, Illner J, Reuter $\mathrm{H}$, Höring $\mathrm{S}$ (1992) Ionic conductivity in poly (ethylene oxide)-poly (alkylmethacrylate)-block copolymer mixtures with Lil. Solid State lon 58(1-2):41-48

29. Aziz SB, Abdulwahid RT, Hamsan MH, Brza MA, Abdullah RM, Kadir MF, Muzakir SK (2019) Structural, impedance, and EDLC characteristics of proton conducting chitosan-based polymer blend electrolytes with high electrochemical stability. Molecules 24(19):3508

30. L Sa'adu, M Hashim, M bin Baharuddin, (2014) Conductivity studies and characterizations of PVA-orthophosphoric electrolytes. J Mater Sci Res 3(3):48

31. Tang C-M, Tian Y-H, Hsu S-H (2015) Poly (vinyl alcohol) nanocomposites reinforced with bamboo charcoal nanoparticles: mineralization behavior and characterization. Materials 8(8):4895-4911

32. Mohan VM, Raja V, Sharma A, Rao VN (2005) lonic conductivity and discharge characteristics of solid-state battery based on novel polymer electrolyte (PEO+ NaBiF4). Mater Chem Phys 94(2-3):177-181 
33. Tsukeshiba $H$, Huang $M, N a Y-H$, Kurokawa T, Kuwabara R, Tanaka Y, Furukawa H, Osada Y, Gong JP (2005) Effect of polymer entanglement on the toughening of double network hydrogels. J Phys Chem B 109(34):16304-16309

34. Schaefer C, van der Schoot P, Michels J (2015) Structuring of polymer solutions upon solvent evaporation. Phys Rev $E$ 91(2):022602

35. Chemical speciation of environmentally significant heavy metals with inorganic ligands. Part 1: The $\mathrm{Hg}^{2+}, \mathrm{Cl}^{-}, \mathrm{OH}^{-}, \mathrm{CO}_{2}{ }^{-3}$, $\mathrm{SO}_{2}{ }^{-4}$, and $\mathrm{PO}_{3}{ }^{-4}$-aqueous systems (IUPAC Technical Report). Pure Appl Chem 77(4):739-800. https://doi.org/10.1351/ pac200577040739

36. Bohnke O, Frand G, Rezrazi M, Rousselot C, Truche C (1993) Fast ion transport in new lithium electrolytes gelled with PMMA 2. Influ lithium salt Conc Solid State lon 66(1-2):105-112

37. Southall J, Hubbard HSA, Johnston S, Rogers V, Davies G, Mclntyre J, Ward I (1996) lonic conductivity and viscosity correlations in liquid electrolytes for incorporation into PVDF gel electrolytes. Solid State Ion 85(1-4):51-60

38. Kobayashi N, Sunaga S, Hirohashi R (1992) Effect of additive salts on ion conductivity characteristics in solid polymer electrolytes. Polymer 33(14):3044-3048

39. N. MOhAME, (2011) lonic conductivity of PEMA-LiClO4 polymer electrolytes. Sains Malaysiana 40(7):701-705

40. Abdullah RM, Aziz SB, Mamand SM, Hassan AQ, Hussein SA, Kadir MFZ (2019) Reducing the crystallite size of spherulites in PEO-based polymer nanocomposites mediated by carbon nanodots and Ag nanoparticles. Nanomaterials 9(6):874

41. Chandra S, Sekhon S, Arora N (2000) PMMA based protonic polymer gel electrolytes. Ionics 6(1-2):112-118

42. Singh HP, Kumar R, Sekhon S (2005) Correlation between ionic conductivity and fluidity of polymer gel electrolytes containing $\mathrm{NH} 4$ CF 3 SO 3. Bull Mater Sci 28(5):467-472

43. Sekhon S, Singh HP (2002) lonic conductivity of PVdF-based polymer gel electrolytes. Solid State Ion 152:169-174

44. De Gennes P-G (1979) Scaling concepts in polymer physics. Cornell University Press, ISBN 080141203X, Bib ID 1021166

45. Hadi JM, Aziz SB, Mustafa MS, Hamsan MH, Abdulwahid RT, Kadir MF, Ghareeb HO (2020) Role of nano-capacitor on dielectric constant enhancement in PEO: $\mathrm{NH} 4 \mathrm{SCN}$ : $x \mathrm{CeO} 2$ polymer nano-composites: Electrical and electrochemical properties. J Mater Res Technol 9(4):9283-9294
46. Isa $M(2016)$ lonic conductivity and electrical properties of carboxymethyl cellulose- $\mathrm{NH} 4 \mathrm{Cl}$ solid polymer electrolytes. J Eng Sci Technol 11(6):839-847

47. Hiemenz PC (1977) Principles of colloid and surface chemistry. Undergraduate Chemistry: A Series of Textbooks, vol. 4. Marcel Dekker, New York-Basel. 1. Aufl., XI, 516 S., geb. SFr. 64.00. https ://doi.org/10.1002/ange.19790910135

48. Aziz SB, Abdullah RM, Rasheed MA, Ahmed HM (2017) Role of ion dissociation on DC conductivity and silver nanoparticle formation in PVA: AgNt based polymer electrolytes: deep insights to ion transport mechanism. Polymers 9(8):338

49. Aziz SB, Abdullah RM, Kadir MFZ, Ahmed HM (2019) Non suitability of silver ion conducting polymer electrolytes based on chitosan mediated by barium titanate (BaTiO3) for electrochemical device applications. Electrochim Acta 296:494-507

50. Aziz SB, Abdullah RM (2018) Crystalline and amorphous phase identification from the tan $\delta$ relaxation peaks and impedance plots in polymer blend electrolytes based on [CS: AgNt] x: PEO $(x-1)(10 \leq x \leq 50)$. Electrochim Acta $285: 30-46$

51. Kim S-K, Koo H-J, Liu J, Braun PV (2017) Flexible and wearable fiber microsupercapacitors based on carbon nanotubeagarose gel composite electrodes. ACS Appl Mater Interf 9(23):19925-19933

52. Jang HS, Raj CJ, Lee W-G, Kim BC, Yu KH (2016) Enhanced supercapacitive performances of functionalized activated carbon in novel gel polymer electrolytes with ionic liquid redox-mediated poly (vinyl alcohol)/phosphoric acid. RSC Adv 6(79):75376-75383

53. Sun K, Ran F, Zhao G, Zhu Y, Zheng Y, Ma M, Zheng X, Ma G, Lei $Z$ (2016) High energy density of quasi-solid-state supercapacitor based on redox-mediated gel polymer electrolyte. RSC Adv 6(60):55225-55232

54. Linh NTB, Lee K-H, Lee B-T (2011) Fabrication of photocatalytic PVA-TiO 2 nano-fibrous hybrid membrane using the electrospinning method. J Mater Sci 46(17):5615-5620

55. Bakar M, Djaider F (2007) Effect of plasticizers content on the mechanical properties of unsaturated polyester resin. J Thermoplast Compos Mater. https://doi.org/10.1177/0892705707068820

Publisher's Note Springer Nature remains neutral with regard to jurisdictional claims in published maps and institutional affiliations. 